\title{
PHOTOGRAMMETRIC SURFACE RECESSION MEASUREMENTS ON ABLATIVE SAMPLES OF VARIOUS SHAPE
}

Thomas Reimer ${ }^{1}$, Stefan Löhle ${ }^{2}$, Rainer Öfele ${ }^{3}$

${ }^{1}$ DLR, German Aerospace Center, Institute of Structures and Design

Pfaffenwaldring 38-40, 70569 Stuttgart, Germany

${ }^{2}$ University of Stuttgart, Institute of Space Systems, Head of High Enthalpy Flow Diagnostics Group, Pfaffenwaldring , 70569 Stuttgart, Germany

${ }^{3}$ University of Stuttgart, Institute of Space Systems, Pfaffenwaldring , 70569 Stuttgart, Germany

Keywords: Photogrammetry, recession, ablation, measurement, high-enthalpy flow

NOMENCLATURE

CMC Ceramic Matrix Composite

CMOS Compementary Metal Oxide Semiconductor

PWK Plasmawindkanal

SURE Photogrammetric Surface Reconstruction from Imagery Software

ZURAM Trade name of ablative DLR material

\begin{abstract}
Results from plasma wind tunnel testing of a lightweight carbon phenolic ablative material are presented. The tests were carried out in a high-enthalpy subsonic flow at a condition corresponding to the Hayabusa re-entry condition in $78 \mathrm{~km}$ altitude. The samples were produced from ZURAM which is a carbon-fiber structure impregnated with phenolic resin. The focus of the investigation was on the measurement method of the recession. Stereoscopic photogrammetry was applied to reconstruct the sample surface in three-dimensional space over the testing time. Two cameras were used to capture images simultaneously. Using a three-step process the sample surface for each image pair was reconstructed and the recession between the image pairs was calculated. The recession resolution is in the range of $45 \mu \mathrm{m}$. The advantage of the method is that the time-resolved in-situ surface recession measurement gives insight into the local recession distribution over the sample surface. This means that recession differences due to the sample geometry or due to material inhomogeneities can be identified. In order to verify this, samples were prepared that include distinct geometric features which influence the recession. Starting with a flat surface cylinder, samples with a rounded surface were prepared as well as a cone-sphere sample and one with a defined indentation in the form of a half-sphere. The temporally and locally resolved recession was successfully measured and related to the sample geometric features.
\end{abstract}

\section{INTRODUCTION}

A spacecraft entering into the atmosphere of Earth or another planet has to withstand severe heat loads which depend on factors like entry speed, vehicle geometry and mass and also the type of atmosphere. A heat shield is used to protect the vehicle from the resulting high heat loads $^{1}$. There are different concepts of heat shields that are used to fulfill the task. Re-usable systems like the heat shield of the Space Shuttle bear the heat load without changing their shape or losing mass which is a good thing with respect to aerodynamics. The disadvantage of these 
systems is that they are partially made from CMC which is relatively expensive to manufacture and maintain and that current materials are limited in their maximum service temperature.

Non-reusable systems like ablators rely on a multitude of effects to deal with the enormous amount of heat ${ }^{2}$. They are good insulators, so the surface temperature is very high which favors radiation and energy consumption takes place due to chemical processes and physical change. In addition there is film cooling due to outgassing and also radiation blocking because of particles transported into the boundary layer.

Ablators are currently the thermal protection systems of choice when the heat loads become very high as e.g. in the case of a superorbital entry like in the case of a moon or mars return $^{3-5}$. A complex set of processes takes place when ablative materials are heated up. Part of the incoming heat is rejected via surface radiation due to the high surface temperature as is the case with re-usable systems, but there are also a lot of processes that consume heat as a result of the material transformation ${ }^{6}$. The materials undergo massive changes and lose a considerable share of their initial thickness. The decrease of the ablator thickness, or in other words, the recession is a critical issue for the design of an ablative heat shield. For a given mission the remaining thickness has to be sufficient to guarantee the effective function as heat shield. The investigation of ablative materials with regard to their thickness loss or recession is usually carried out with measurements before and after a test, most often done in arc jet facilities. Since missions become more demanding and the design of the space vehicles increasingly sophisticated, the understanding of the TPS materials needs to be improved to be able to reduce margins to meet the mission mass targets. Therefore, the aim of this work was to get more detailed information out of tests, specifically the local time-resolved recession rate of ablative materials.

\section{MATERIAL AND SAMPLES}

The For this study, two types of material were tested. For an initial test, a carbon preform material was used. After that, dedicated samples made from the carbon phenolic lightweight ablative material Zuram were manufactured. Although there is a wide range of ablators with different compositions and properties used for different kinds of entry missions, these materials are hard to get by. Therefore, DLR recently has begun to develop its own ablative material in order to enlarge the range of available heat shield materials.

\section{Carbon felt and ablative material}

The carbon preform material is CALCARB ${ }^{\circledR}$, a commercial thermal insulation product from the Mersen company which was chosen to have an uncomplex material with a relatively high recession rate and known properties. It was used before in similar investigations ${ }^{7}$.

The ablative material that was used for the investigations is ZURAM ${ }^{\circledR}$ which is a lightweight ablative material with a density of $0.36 \mathrm{~g} / \mathrm{cm}^{3}$, designed for high enthalpy entry missions. Employing a specific manufacturing process, a nanoscale phenolic foam is created in the carbon-phenolic-based material. The microstructure of the phenolic foam results in high damage tolerance of the composite with a compression strength of $6.9 \mathrm{MPa}$ at a compression strain of 0.39 . In arc jet tests at enthalpies of $13.5 \mathrm{MW} / \mathrm{m}^{2}$ and a pressure of $675 \mathrm{hPa}$, average values for the mass loss and recession rate were $0.323 \mathrm{~g} / \mathrm{s}$ and $0.308 \mathrm{~mm} / \mathrm{s}$ respectively. The thermal conductivity of the uncharred material is $0.18 \mathrm{~W} / \mathrm{mK}$ at ambient conditions.

\section{Samples}

The carbon felt sample was cylindrical with a diameter of $40 \mathrm{~mm}$, a flat face and a center borehole for additional spectroscopic measurements on the stagnation streamline ${ }^{8}$. 
As the intention of the work was to demonstrate the potential of the measurement method to resolve the sample recession over time and space, sample shapes were chosen that would show an unevenly distributed recession over the surface. All samples were of a cylindrical shape with different front surface geometries. As the basic case a sample with a flat face was selected. Additional surface geometries included a conical shape with a rounded tip and a spherical face. The spherical front was chosen along the considerations for a sample shape adapted to the flowfield in a supersonic test facility in order to have a resulting uniform heat load over the surface. The shape that has been suggested from these considerations is called Iso-q shape and was proposed by Milos and Chen ${ }^{9}$. As a variation of that shape, a sample with an elliptical front surface cross section was also included. This shape was proposed as an improvement with regard to the heat load distribution in supersonic flow. The semi-major of the ellipse is defined as the cylinder radius $R$, the semi-minor as $\mathrm{R}(1-\sqrt{3} / 2)$. Finally, as a shape to contrast the conical sample, an Iso-q sample was produced that featured a spherical indentation in the stagnation region. Table 1 gives an overview of the samples used in the test campaign and Fig. 1 shows the geometries of the tested samples.

Table I: Overview of sample shapes.

\begin{tabular}{llccl}
\hline \hline Material & Surface Geometry & Diameter & Height & Details \\
\hline & & $\mathrm{mm}$ & $\mathrm{mm}$ & \\
\hline Carbon felt & Flat & 50 & 40 & \\
ZURAM & Flat & 50 & 40 & Edge radius $3.125 \mathrm{~mm}$ \\
ZURAM & Spherical & 50 & 40 & Sphere radius $50 \mathrm{~mm}$ \\
ZURAM & Spherical, indentation & 50 & 40 & Indentation depth $5 \mathrm{~mm}$ \\
ZURAM & Elliptical & 50 & 40 & Semi-minor: $R(1-\sqrt{3} / 2)$ \\
ZURAM & Conical, round tip & 50 & 40 & Cone angle $135^{\circ}$, tip radius $5 \mathrm{~mm}$ \\
\hline \hline
\end{tabular}

\section{PHOTOGRAMMETRY}

Photogrammetry is applied to retrieve non-intrusively three-dimensional geometric data from two-dimensional images from image pairs. Nevertheless, more than two images can be used and do in fact increase accuracy ${ }^{10}$. The absolute sizes of the objects are no limitation to the
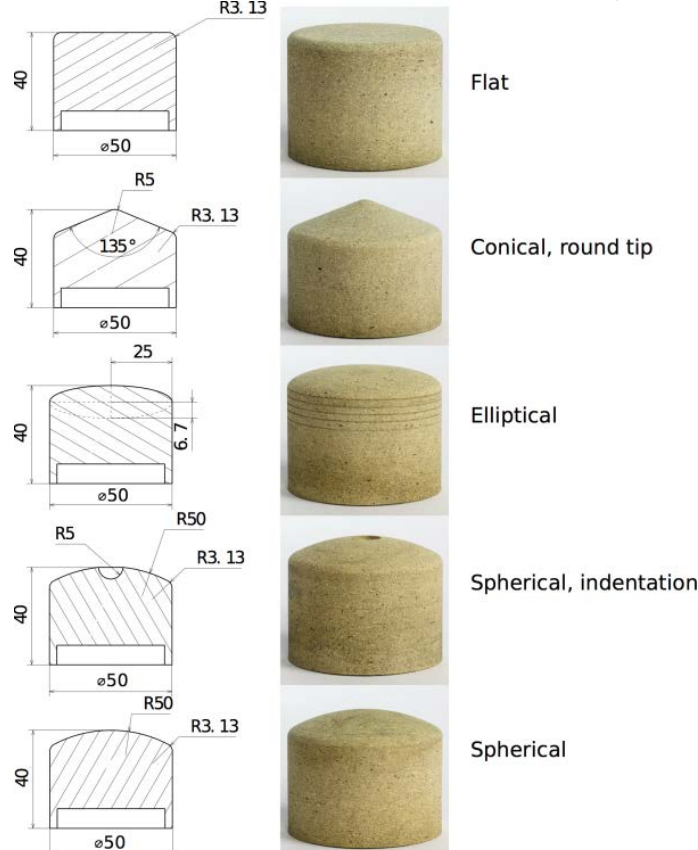

Figure 1: Tested ZuRAM sample geometries. method. Photogrammetry is applied in air and space imagery as well as in near-field applications. In order to be able to calculate three dimensional objects from two-dimensional images, the images have to be central projections. A central projection is the twodimensional representation of three-dimensional objects. In contrast to a parallel projection, the projection rays that connect object points with the projection plane meet in the same point, the center of projection. In that way each object point is related to an image point. To be able to describe the projection rays in three-dimensional space, the internal and external orientation of all cameras must be known. The system is calibrated with an appropriate test object. The calibration in the present work was realised with the commercial product Agisoft PHOTOSCAN. The 
measured data is analysed using SURE ${ }^{11}$. The theory of photogrammetry shall not be detailed further in this work, the process has been described in a previous publication ${ }^{7}$. Photogrammetric recession measurements were previously done by another group using a different technique ${ }^{12}$.

\section{EXPERIMENTAL SETUP}

The experiments were performed in the plasma wind tunnel facility PWK 1 at the Institute of Space Systems of the University of Stuttgart. This facility is used to simulate the aerothermal situation that materials are facing during an atmospheric entry manoeuver ${ }^{13,14}$. A high enthalpy flowfield is established using an appropriate generator and the samples are positioned in this flowfield at positions that correspond to the heat flux and total pressure of the flight condition. Diagnostic methods can be applied outside the vessel when sufficient and useful windows are available. The camera system for the photogrammetry is mounted on tripods to observe the sample surface through windows in the front lid ${ }^{6}$.

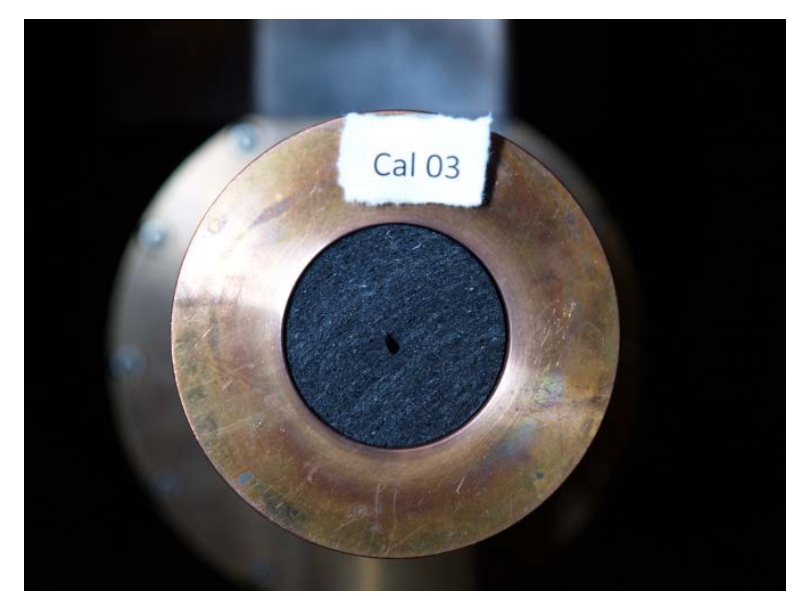

Figure 2: Probe with mounted CALCARB sample.

The present investigation was conducted with different geometries tested in this way for the first time in the facility. The conventional probe technique which is used in the present investigation for the carbon preform is used regularly for ablation material testing (see e.g. ${ }^{8,15,16}$ ). Fig. 2 shows a photo of the sample as mounted in the sample holder. Further details of this setup are described in ${ }^{7}$.

The chosen flow condition was developed for ground test analysis of the observed Hayabusa re-entry in $2010^{13,17}$. The parameters of the chosen flow condition are summarized in Table 2. Heat flux and total pressure were measured in separate tests using the same probe geometry. Heat flux is derived from a calorimetric cold wall heat flux measurement on a preoxidized copper surface.

Table 2: Plasma wind tunnel condition corresponding to Hayabusa at $78.8 \mathrm{~km}$.

\begin{tabular}{lc}
\hline \hline Parameter & Value \\
\hline mass flow $\dot{m}$ & $18.0 \mathrm{~g} / \mathrm{s}$ \\
ambient pressure $p_{\infty}$ & $16.6 \mathrm{hPa}$ \\
total pressure $p_{\text {tot }}$ & $24.3 \mathrm{hPa}$ \\
arc current $I$ & $1220 \mathrm{~A}$ \\
arc voltage $U$ & $133 \mathrm{~V}$ \\
electric power $P$ & $162 \mathrm{~kW}$ \\
probe position & $\mathrm{x}=270 \mathrm{~mm}, \mathrm{y}=0 \mathrm{~mm}$ \\
heat flux $Q^{\cdot}$ & $4100 \mathrm{~kW} / \mathrm{m}^{2}$ \\
\hline \hline
\end{tabular}


There are only small optical windows to observe the plasma flow and the probe. Fig. 3 shows a photograph and a schematic of the setup using two cameras. A possible influence of the windows with respect to the photogrammetric measurements was analysed during previous work $^{19}$. In this configuration the angle between the imaging axis of the two cameras was between $95^{\circ}$ and $100^{\circ}$. Depending on other instruments used in the experiment, the distance between probe and camera varies between $2.8 \mathrm{~m}$ and $4.0 \mathrm{~m}$. A closer position is preferable, but is restricted by the space required to open the front lid of the vacuum vessel.
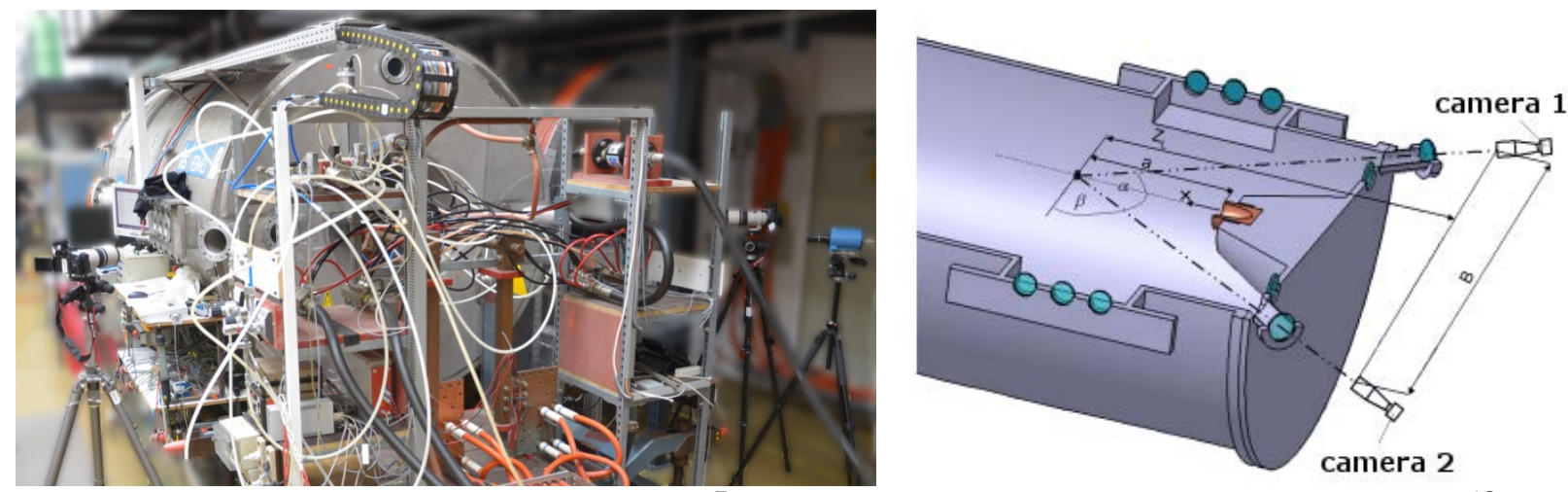

Figure 3: Plasma wind tunnel PWK 1 (left) $^{7}$ and geometry for the photogrammetry (right) ${ }^{18}$.

\section{CAMERA AND SAMPLE SETUP}

The tests were carried out in the plasma wind tunnel PWK 1 of the Institute of Space Systems at the University of Stuttgart. The setup is a triangle with two cameras symmetrically positioned at an angle of approximately $50^{\circ}$ to the axis where the sample is positioned as depicted in Fig. 3.

To acquire the images, two identical Canon EOS 60D DSLR cameras were used in combination with Canon EF 300mm 1:4,0 L IS USM telephoto lenses shown in Fig. 4. In some cases an additional Extender EF 1.4x III was used to increase the focal length by a factor of 1.4. The cameras were mounted on sturdy tripods to minimize vibration during exposure. A threeaxis geared tripod head was very helpful in adjusting the exact pointing tojwards the sample. The camera has a CMOS sensor with a size of 22.3 by $14.9 \mathrm{~mm}$ corresponding to a resolution in pixels of 5184 by 3456. It was desired to take images at a high frame rate. The camera supports

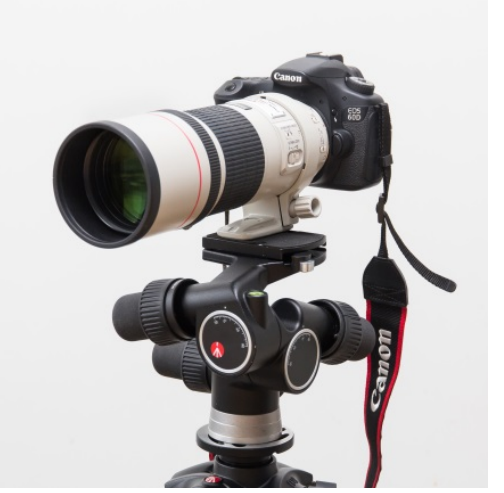

Figure 4: Camera with lens on tripod head. a maximum frame rate of 5 images per second, however, when the image quality is set to the raw-format with a large file size, that rate cannot be kept for long. Therefore, the images were saved as jpeg-files at a rate of 3 frames per second which allowed for continuous operation. Both cameras were triggered at the same time via a pulse generator. The brightness of the heated sample front during testing was known roughly from previous tests at comparable conditions, so neutral density gray filters ND 1.2 were used which reduce the intensity of the transmitted light to $6.3 \%$ to arrive at feasible exposure settings. The cameras were controlled via a computer interface to avoid disturbing their position after the calibration.

The calibration procedure required a total of 20 image pairs of a calibration object taken under different angles. The calibration plate that was used included a scale to have the size information available. 


\section{DATA PROCESSING}

In a first step the commercial software AgISOFT Photoscan was used to calibrate the setup. PHOTOSCAN can actually also generate three-dimensional object representations, however, for this purpose it was only used to establish the camera calibration data with the orientations which was then used by another tool in a following step. The images were cut to have the sample fill the complete image. It was important to cut all the images in the same way since that has an influence on the photogrammetric processing. Then the local contrast of the images was increased using a standard image editing tool. Experience had shown that a moderate contrast increase resulted in a higher success rate for the photogrammetry software to find corresponding points in the image pairs.

Using the calibration data from PHOTOSCAN, SuRE calculated high-resolution point clouds from the images. SURE is a software developed by the Institute of Photogrammetry of the University of Stuttgart. The software processes every image pair separately. First the images are rectified and orientated. Then corresponding image points are identified on the basis of epipolargeometric calculations. For every image pair a point cloud is calculated. Thereby, a consecutive set of point clouds is generated which represent ablation of the sample over time. The point clouds were processed further with CLOUDCOMPARE to bring all the point clouds in relation to each other and to do distance calculations. The first point cloud is used as the reference for all the following time steps. The actual data evaluation in terms of recession and recession rate and their visualization was calculated with MATLAB.

In the following, data is presented for the total recession of the sample and the corresponding recession rate over time. For the analysis in this work, the simplifying assumption was made that the recession would be rotationally symmetric over the sample axis. So, the surface of the sample was divided into circular areas of even spacing and each circular area was averaged. Each averaged value for one circular area is given in the discussion of the recession rate over the sample radius. For the evaluation of the total recession the averaged values of each circular area were taken and averaged with a weighting regarding the area of each, arriving at one value for the total recession of the sample over time. The assumption of a symmetric condition was verified with the test data from the carbon felt sample. One of the circular areas was further divided into sub-sections which were compared with regard to the recession data. The result indicated that the assumption was justified.

\section{RESULTS}

The experiments were successful with the carbon felt sample, the flat and spherical samples and the indented spherical sample. In the case of the sample with elliptical surface the data could not be evaluated because of a glitch during the setup of the cameras; the images of one camera did not capture the sample fully. In the case of the conical sample it was realized during the data processing that the cone angle was apparently still too small - i.e. the cone was too pointed - and the recession data could not be calculated.

\section{CARBON PREFORM}

The carbon felt sample was tested for $60 \mathrm{~s}$. The measured recession rate increased from $56.0 \mu \mathrm{m} / \mathrm{s}$ to $59.4 \mu \mathrm{m} / \mathrm{s}$ which is almost constant over time and a mean value of $57.7 \mu \mathrm{m} / \mathrm{s}$. Corresponding to that, the total recession increased in a linear way to $3.36 \mathrm{~mm}$ as shown in Fig. 5. 


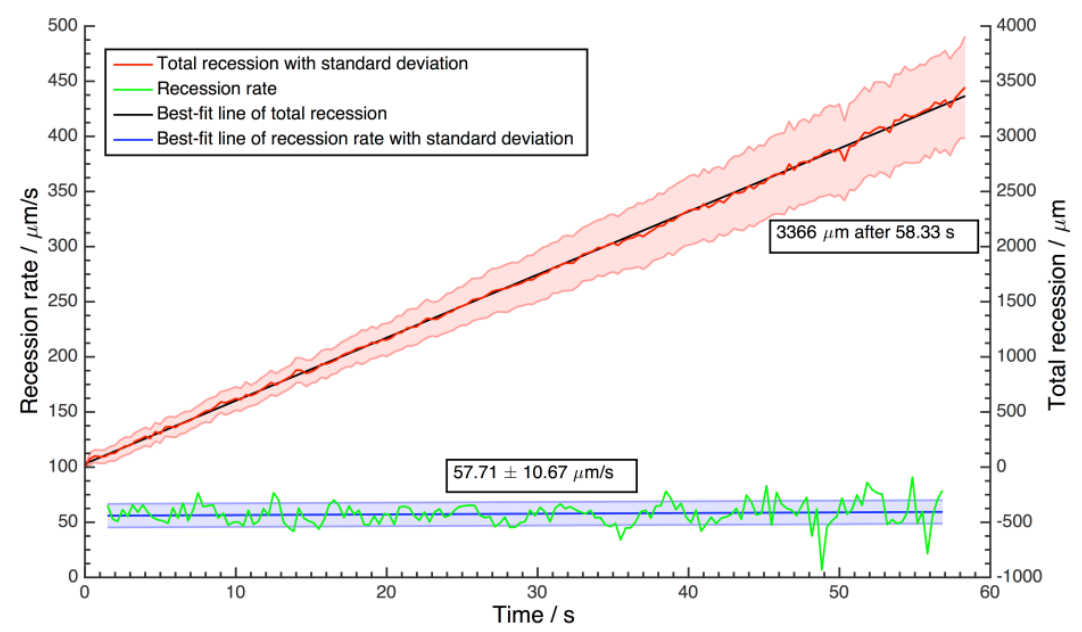

Figure 5: Total recession and recession rate of the carbon felt sample over time.

The distribution of the recession and the recession rate over the radius of the sample is shown in Fig. 6. From Fig. 6 it can be noted that the recession was strongest in the center of the sample leading to a distinctive washout.

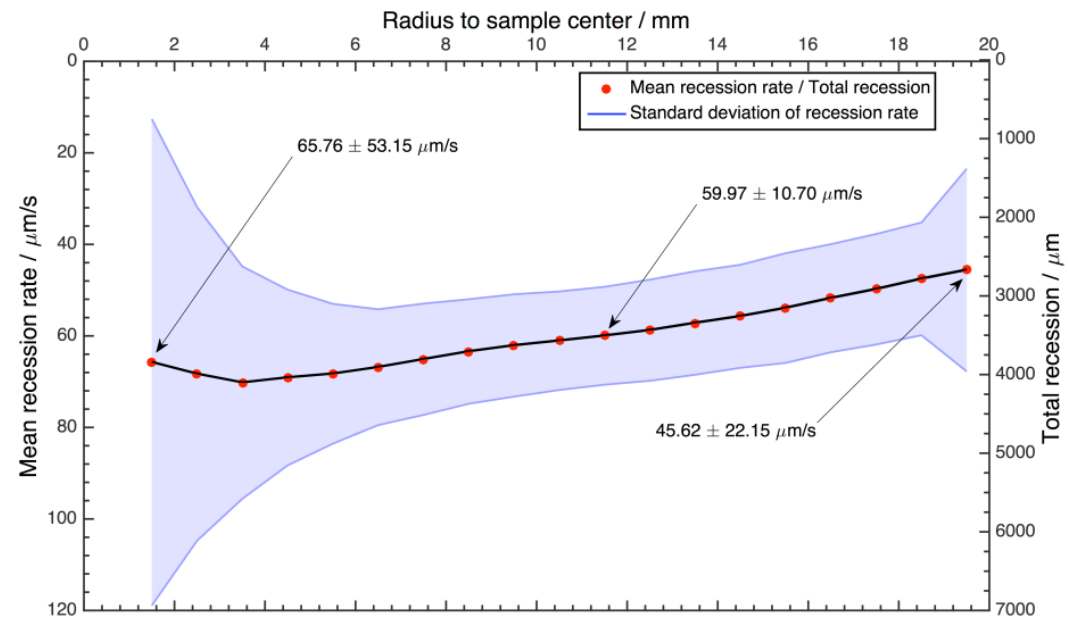

Figure 6: Total recession and recession rate over the radius of the carbon preform sample.

\section{FLAT SAMPLE}

The flat sample was the first ZURAM sample that was tested. The test duration was $60 \mathrm{~s}$ but after $30 \mathrm{~s}$ the fixation of the sample to the model holder failed so that only the first $25 \mathrm{~s}$ can be regarded as useful for the analysis. Therefore, for all remaining samples the test time was reduced to $25 \mathrm{~s}$. When this time span is considered, the recession rate increases slightly from $42.4 \mu \mathrm{m} / \mathrm{s}$ to $43.8 \mu \mathrm{m} / \mathrm{s}$, with a mean value of $42.95 \mu \mathrm{m} / \mathrm{s}$. The total recession is $1.07 \mathrm{~mm}$ as presented in Fig. 7.

When a regression line is fitted to the recession rate curve, it is almost at a constant value and has a slope of only $0.06 \mu \mathrm{m} / \mathrm{s}$ over the test time which is negligible, so the recession rate is practically constant over the first $25 \mathrm{~s}$ of the test. Also, the standard deviation of the recession rate is smaller when compared to the carbon felt sample. 


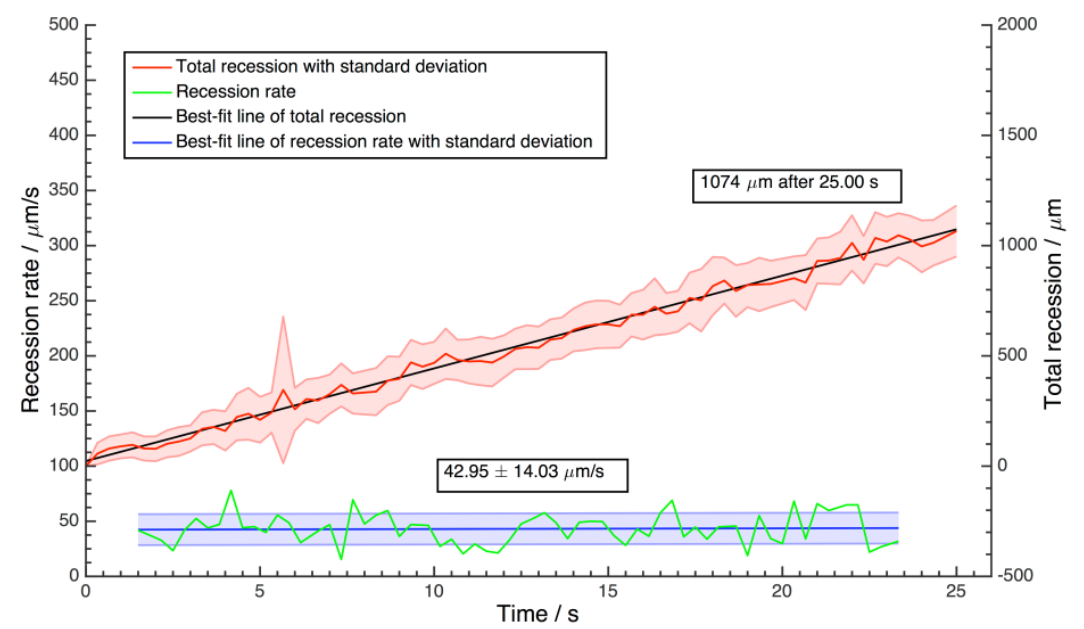

Figure 7: Total recession and recession rate over time for the flat sample.

The recession rate and the total recession are almost constant over the radius of the sample. The recession rate in the center is $44.5 \mu \mathrm{m} / \mathrm{s}$, falling slightly to $40.4 \mu \mathrm{m} / \mathrm{s}$ at the sample edge, shown in Fig. 8. This is explained with the fact that the sample geometry and the freestanding position in the flow lead to more homogeneous ablation conditions on the sample surface when compared to the setup with the metallic holder.

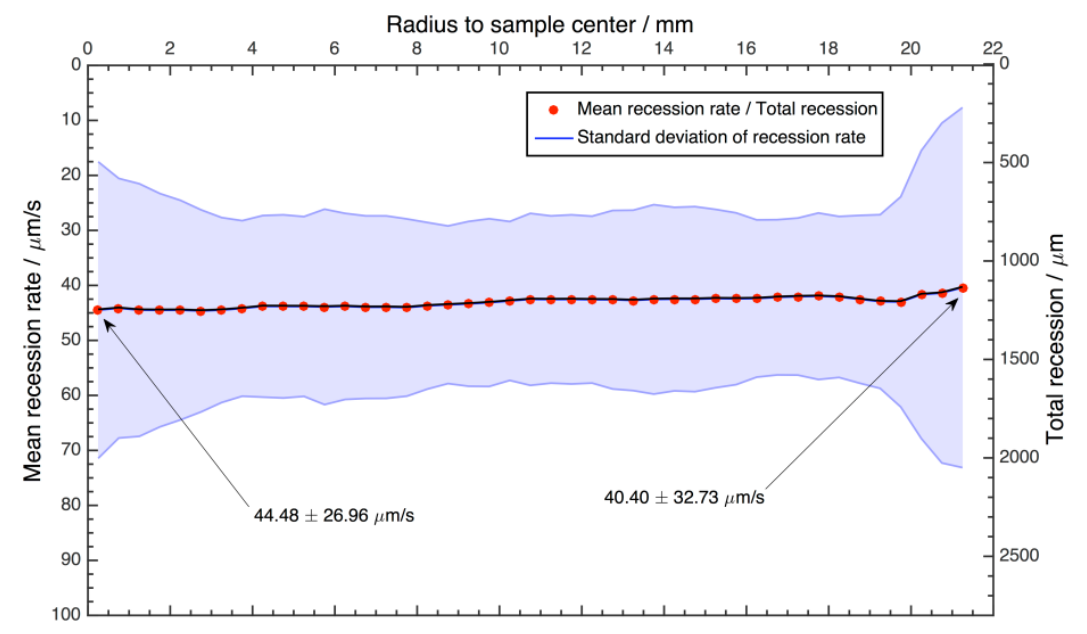

Figure 8: Total recession and recession rate over the radius of the flat sample.

\section{SPHERICAL SURFACE SAMPLE}

In the case of the sample with spherical surface the recession rate decreased over time from $53.3 \mu \mathrm{m} / \mathrm{s}$ to $33.8 \mu \mathrm{m} / \mathrm{s}$ as shown in Fig. 9. The total recession at the end of the test was $1.28 \mathrm{~mm}$. Fig. 10 shows that the average recession rate over the sample radius is not constant. In the sample center it is $70 \mu \mathrm{m} / \mathrm{s}$, whereas it is only $32 \mu \mathrm{m} / \mathrm{s}$ at the edge of the sample. This observation can be explained with an uneven distribution of the heat load over the sample surface. Obviously the spherical shape is not well suited for subsonic flows if a constant heat load over the surface is desired. 


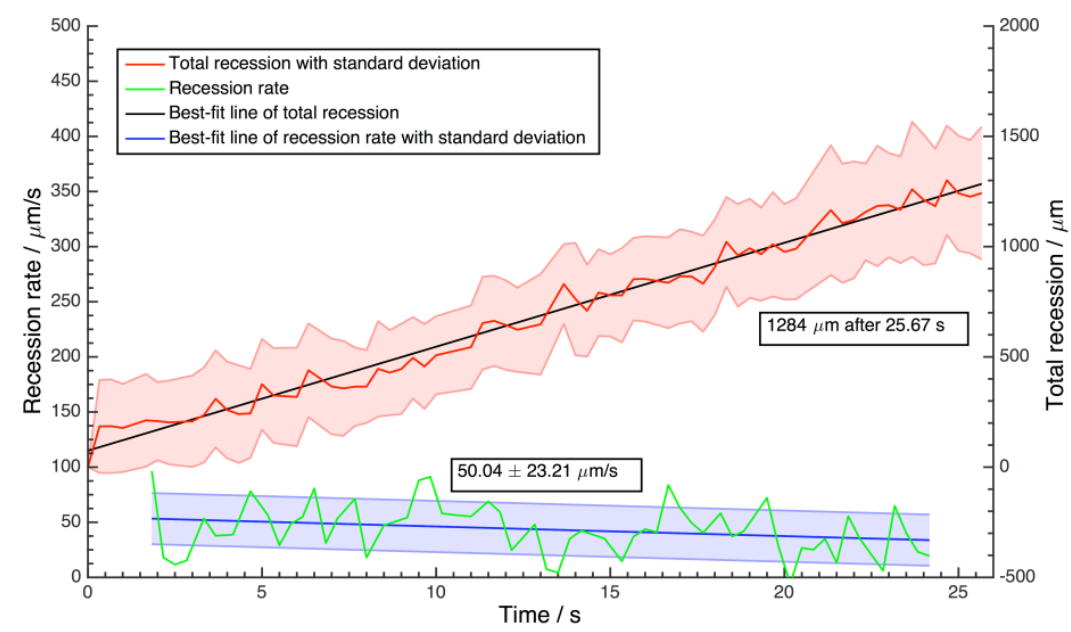

Figure 9: Total recession and recession rate over time for the spherical surface sample

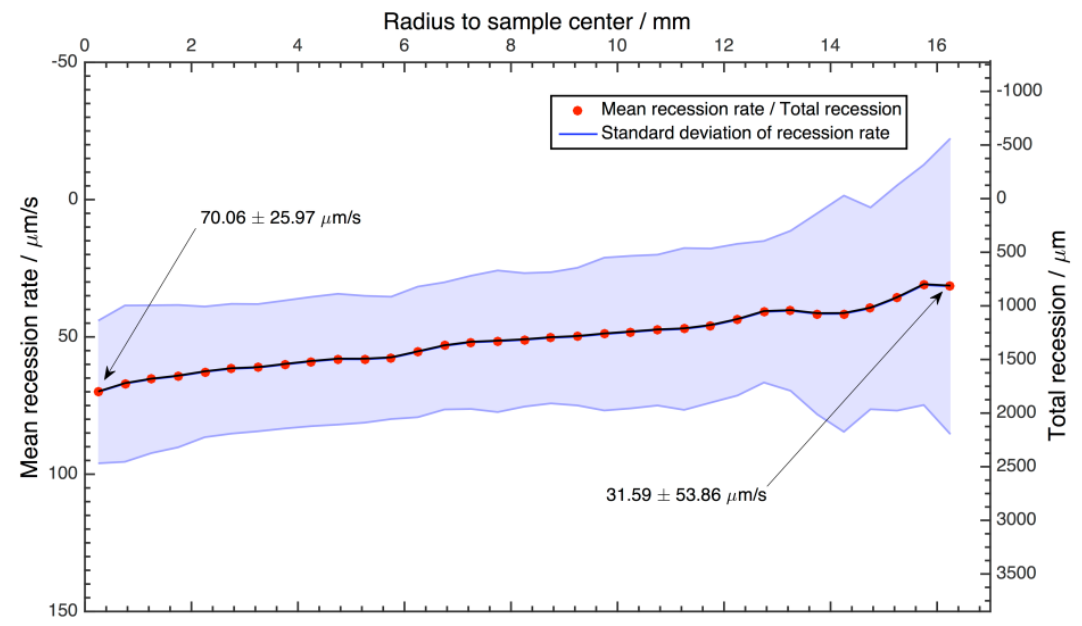

Figure 10: Total recession and recession rate over the radius of the spherical sample.

\section{SPHERICAL SURFACE SAMPLE WITH CENTER INDENTATION}

The indentation was introduced in the sample to have a shape which is certainly experiencing non-constant heat load and thus greater differences in recession over the surface. The indentation had the shape of a half-sphere with $5 \mathrm{~mm}$ radius which was also the depth measured from the theoretical tip of the non-indented sample. In terms of the recession measurements it was expected that the inner surface of the indentation could not be evaluated completely, which was indeed the case due to the fact that each camera can only see a certain part of the inner indentation surface and vice versa. In addition it has to be considered that the indentation remains relatively cool and thus dark at the beginning of the test so that SURE has trouble in finding points in the beginning and those that are calculated have a greater uncertainty about them. The average recession rate in the regions that can be evaluated is $62 \mu \mathrm{m} / \mathrm{s}$, which seems to be due to the influence of the indentation. The slope of the regression curve through the rate data is $-0.91 \mu \mathrm{m} / \mathrm{s}$, which is on the same level as that for the same shape without indentation. However, the standard deviation of the recession rate is higher at $44 \mu \mathrm{m} / \mathrm{s}$, which is attributed to the complex contour shown in Fig. 11. 


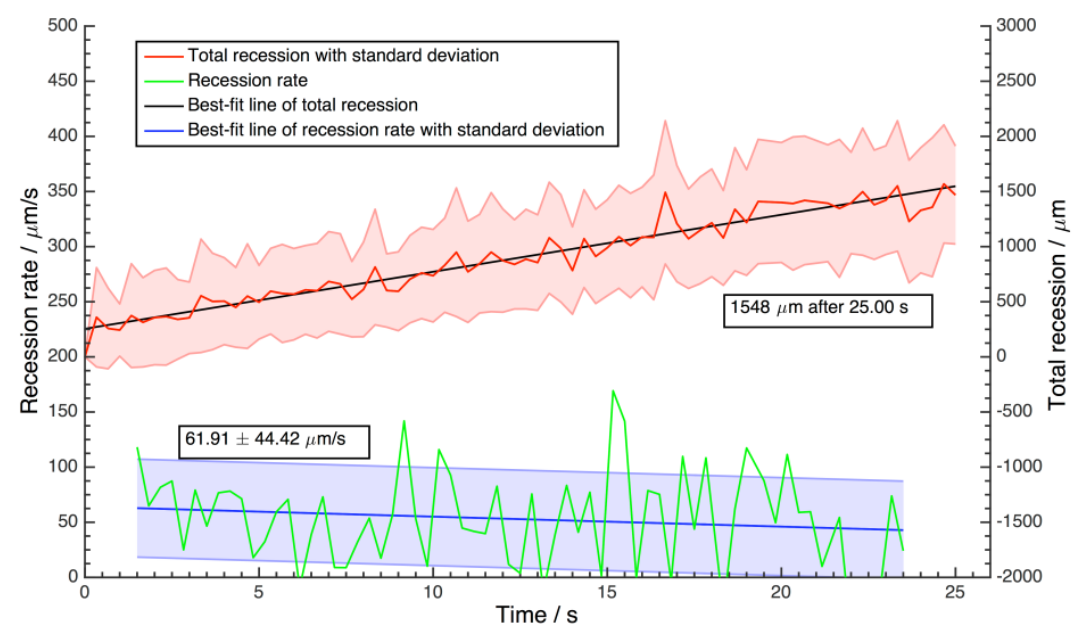

Figure 11: Total recession and recession rate over time for the indented spherical sample.

The distribution of the recession rate over the sample radius as given in Fig. 12 shows the influence of the indentation. In the sample center, on the bottom of the indentation, a recession rate of almost $150 \mu \mathrm{m} / \mathrm{s}$ is calculated, however, the large error values of $+/-200 \mu \mathrm{m} / \mathrm{s}$ indicate that this value is unreliable. At the edge of the indentation, the recession rate is $99 \mu \mathrm{m} / \mathrm{s}$, with a standard deviation that is down to $66 \mu \mathrm{m} / \mathrm{s}$ which is still comparatively high but in the order of values obtained for the other samples. To the edge of the sample the rate decreases to $44 \mu \mathrm{m} / \mathrm{s}$.

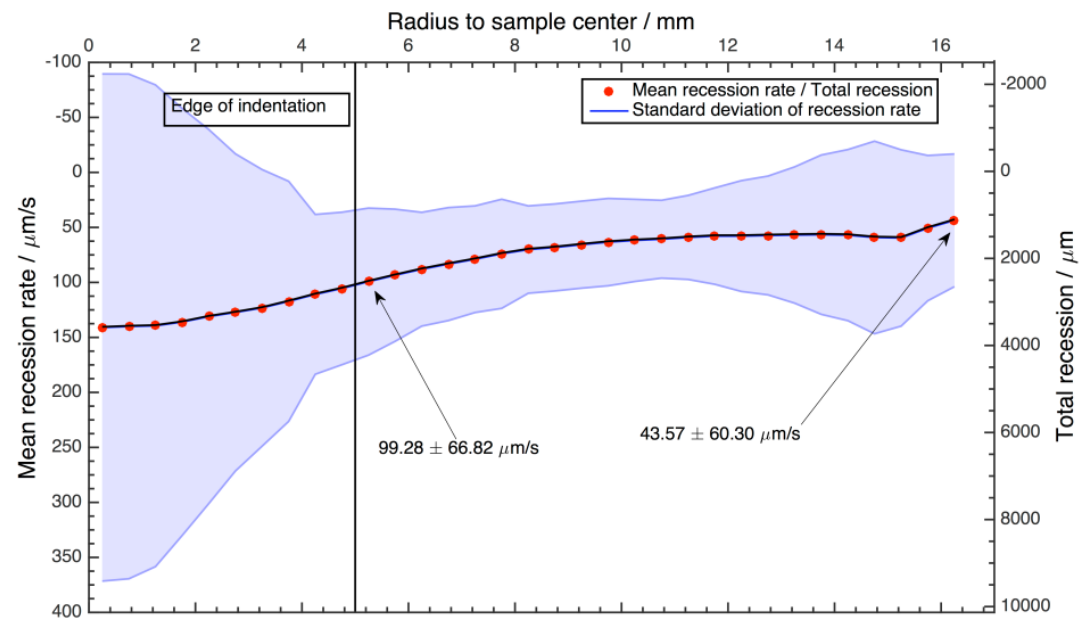

Figure 12: Total recession and recession rate over the radius of the indented spherical sample

It was assumed that the recession is quite transient for this sample, so the analysis was repeated with two different evaluation time intervals. The first one comprised the time from the beginning of the test up to $12.3 \mathrm{~s}$, given in Fig. 13, the second one the remaining time up to the test end at $25 \mathrm{~s}$, given in Fig. 14. There is indeed a difference when the recession rate in the same location is compared. At the indentation edge the recession rate for the first evaluation interval was $115 \mu \mathrm{m} / \mathrm{s}$ whereas it is only $94 \mu \mathrm{m} / \mathrm{s}$ for the second interval, compared to the average of $99 \mu \mathrm{m} / \mathrm{s}$ for the whole test. 


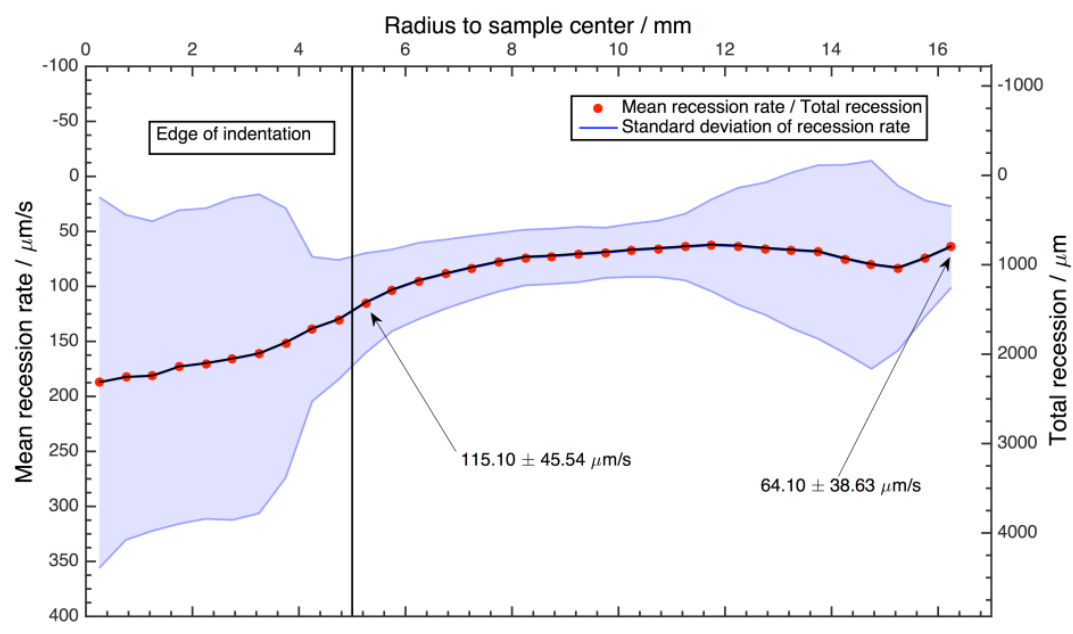

Figure 13: Total recession and recession rate over the radius of the indented sample evaluated over the first $12.3 \mathrm{~s}$ of the test.

A similar observation can be made for the sample edge where the rate for the first interval is $64 \mu \mathrm{m} / \mathrm{s}$ and $43 \mu \mathrm{m} / \mathrm{s}$ for the second interval, compared with $44 \mu \mathrm{m} / \mathrm{s}$ for the whole test, see Fig. 13 and Fig. 14. In addition to the points mentioned above, it was observed that the average recession rate during the first half of the test was approximately $20 \mu \mathrm{m} / \mathrm{s}$ higher than during the second half of the test.

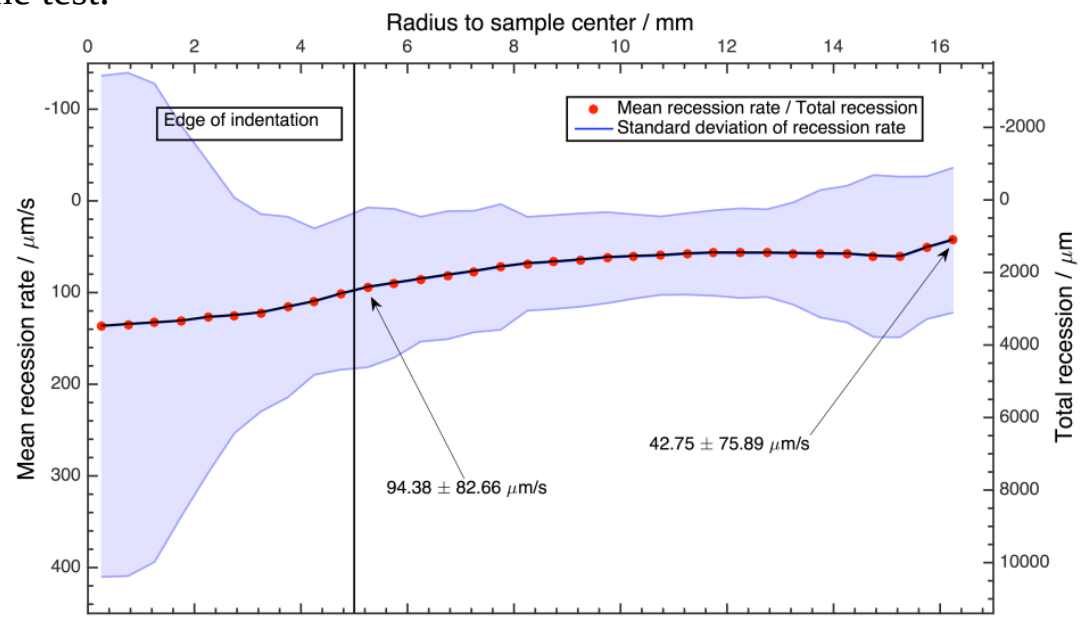

Figure 14: Total recession and recession rate over the radius of the indented sample evaluated over the time from $12.3 \mathrm{~s}$ to $25 \mathrm{~s}$.

Since the edge of the indentation was the region with the highest recession values, this region was analyzed in more detail. A circular region between the radii 5.5 and $6.0 \mathrm{~mm}$ was considered - the indentation radius itself was $5.0 \mathrm{~mm}$. The intention was to select an evaluation region with a slightly larger radius to avoid any problems with areas not visible by one of the cameras. The results given in Fig. 15 show that the recession rate at the indentation edge is $119.4 \mu \mathrm{m} / \mathrm{s}$ in the beginning and then drops to a value of $64.8 \mu \mathrm{m} / \mathrm{s}$ towards the end of the test. This is a change of $-2.5 \mu \mathrm{m} / \mathrm{s}^{2}$ which is the highest change in the recession rate measured. 


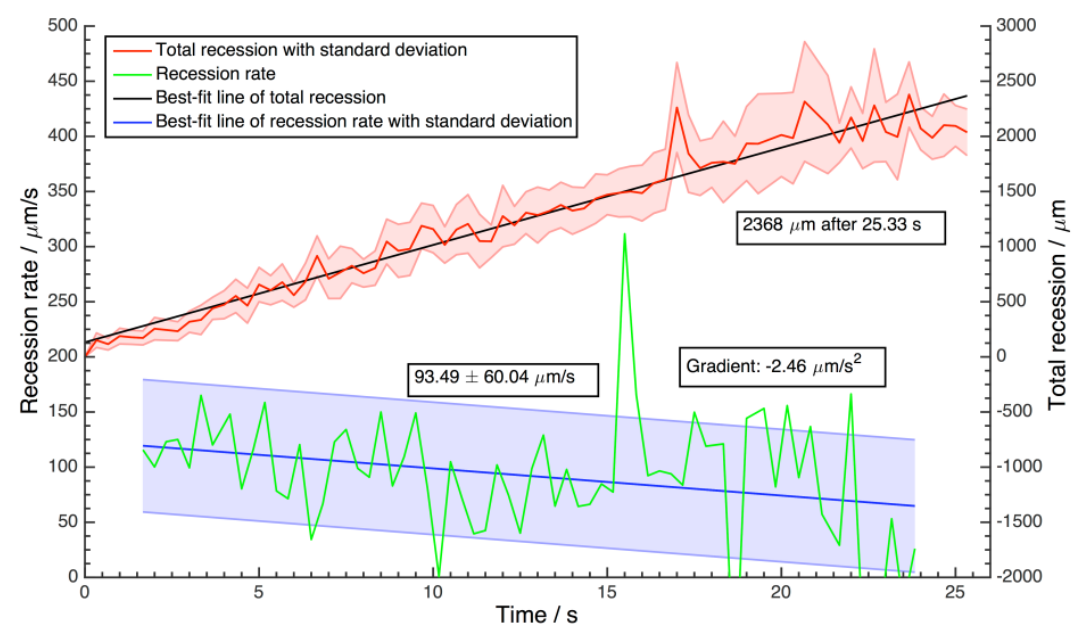

Figure 15: Total recession and recession rate over time for the indented spherical sample evaluated at the edge of the indentation.

\section{CONCLUSION}

An investigation of the recession of different geometries of a lightweight carbon phenolic ablator material was conducted. Using a photogrammetric setup, the recession behavior was investigated to a high level of detail. The selected geometries proved to yield interesting results. As for the surface shape, it was evident that the Iso-q geometry does indeed only lead to constant surface heat load in a supersonic flow. Of the investigated shapes, the flat faced sample was closest to a constant surface heat load for the subsonic flow conditions in the tests. The indented sample showed that very localized phenomena can be investigated.

It can be concluded that the method allows to identify surface effects arising from surface inconsistencies and geometrical defects. This is of particular importance when materials are tested for future flight scenarios. For future material investigations with the focus on material properties, a flat faced sample should be considered to allow for homogeneous recession and thus a distinct experimental situation.

The goal for further development of the measurement method is to calculate the recession rate for smaller time intervals, ideally the momentary rate as the derivative of the recession and to do this with a higher degree of discretization over space.

\section{ACKNOWLEDGEMENTS}

The helpfulness of Christian Zuber from DLR is acknowledged for providing the ZURAM material batch.

\section{REFERENCES}

${ }^{1}$ Lu, F. K. and Marren, D. E., editors, Advanced Hypersonic Test Facilities, Progress in Astronautics and Aeronautics, 198, AIAA, 2002.

${ }^{2}$ Lachaud, J., Cozmuta, I., and Mansou, N. N., Multiscale Approach to Ablation Modeling of Phenolic Impregnated Carbon Ablators, Journal of Spacecrafts and Rockets, 47, No. 6, 2010.

${ }^{3}$ Johnston, C. O., Gnoffo, P. A., and Sutton, K., Influence of Ablation on Radiative Heating for Earth Entry, Journal of Spacecrafts and Rockets, 46, 2009, pp. 481-491. 
${ }^{4}$ Wright, M. J., Grinstead, J. H., and Bose, D., A Risk-Based Approach for Aerothermal/TPS Analysis and Testing, Experiment, Modeling and Simulation of Gas-Surface Interactions for Reactive Flows in Hypersonic Flights, 17, RTO, 2007.

${ }^{5}$ Wright, M. J., Tang, C. Y., Edquist, K. T., Hollis, B. R., Krasa, P., and Campbell, C. A., A Review of Aerothermal Modeling for Mars Entry Missions, 2010.

${ }^{6}$ Löhle, S., Hermann, T., Zander, F., Fulge, H., and Marynowski, T., Ablation Radiation Coupling Investigation in Earth Re-entry Using Plasma Wind Tunnel Experiments, 30th Aerodynamic Measurement Technology and Ground Testing Conference, AIAA, 2014. ${ }^{7}$ Löhle, S., Staebler, T., Reimer, T., and Cefalu, A., Photogrammetric Surface Analysis of Ablation Processes in High Enthalpy Air Plasma Flow, 30th Aerodynamic Measurement Technology and Ground Testing Conference, AIAA, 2014, accepted for publication.

${ }^{8}$ Hermann, T., Zander, F., Fulge, H., Löhle, S., and Fasoulas, S., Characterization of a Re-entry Plasma Wind Tunnel Flow with Vacuum Ultraviolet to Near Infrared Spectroscopy, Journal of Thermophysics and Heat Transfer, 2015, submitted.

${ }^{9}$ Milos, F. S. and Chen, Y.-K., Ablation and Thermal Response Porperty Model Validation for Phenolic Impregnated Ablator, AIAA Journal of Spacecrafts and Rockets, 47, No. 5, 2010.

${ }^{10}$ Luhmann, T., Nahbereichsphotogrammetrie: Grundlagen, Methoden und Anwendungen, Wichmann, Berlin, 3rd ed., 2010.

${ }^{11}$ Rothermel, M., Wenzel, K., Fritsch, D., and Haala, N., SURE: Photogrammetric Surface Reconstruction from Imagery, Berlin, Dec. 2012.

${ }^{12}$ Schairer, E. T. and Heineck, J. T., Photogrammetric Recession Measurements of Ablative Materials in Arcjets, Measurement Science and Technology, 21, 2010.

${ }^{13}$ Löhle, S., Brandis, A., Hermann, T., and Peter, J., Numerical Investigation of the Re-entry Flight of Hayabusa and Comparison to Flight and Ground Testing Data, 43rd AIAA

Thermophysics Conference, AIAA, LA, 2012.

${ }^{14}$ Auweter-Kurtz, M. andWegmann, T., Overview of IRS PlasmaWind Tunnel Facilities, $R T O$ Educational Notes, 8, Oct. 1999.

${ }^{15}$ Eswein, N., Herdrich, G., Fasoulas, S., and Röser, H.-P., Investigation of Graphite Ablation at IRS, 42nd Thermophysics Conference, AIAA, 2011.

${ }^{16}$ Wernitz, R., Eichhorn, C., Herdrich, G., Löhle, S., Fasoulas, S., and Röser, H.-P., Plasma Wind Tunnel Investigation of European Ablators in Air Using Emission Spectroscopy, 42nd AIAA Thermophysics Conference, 2011.

${ }^{17}$ Löhle, S. and Jenniskens, P., High Resolution Spectroscopy of the Hayabusa Re-entry using a Fabry-Perot Interferometer, Journal of Spacecrafts and Rockets, 51, No. 6, 2014.

${ }^{18}$ Marr, J., Untersuchung von photogrammetrischen Methoden zu in-situ Oberflächenanalyse von Ablatoren, Diplomarbeit, Universität Stuttgart, 2011, IRS-11-S18.

${ }^{19}$ Pitzer, P., Einfluss refraktiver und reflektiver Elemente auf die photogrammetrische Kamerakalibrierung, Bachelorarbeit, Universität Stuttgart, 2012. 